\title{
Prescribing for pain - how do nurses contribute? A national questionnaire
}

\section{survey}

K. Stenner, PhD, BSc. (hons), Research Fellow, School of Health and Social Care, University of Surrey

N. Carey, PhD, MPH, BSc. (hons), RGN, RM, Senior Research Fellow, School of Health and Social Care, University of Surrey

M. Courtenay, Phd, MSc, RGN, Cert. Ed. Professor of Clinical Practice: Prescribing and Medicines Management, School of Health and Social Care, University of Surrey

\section{Corresponding author:}

Karen Stenner, Research Fellow,

School of Health and Social Care,

University of Surrey, Guildford

GU2 7TE

Tel: $01483683242 \quad$ Fax: 01483686711

Email: k.stenner@surrey.ac.uk

\section{Acknowledgement}

We would like to warmly thank those who participated in this survey. Support for this project was provided by NAPP pharmaceuticals. There was no influence over the study design, conduct or reporting of findings on behalf of NAPP pharmaceuticals.

\section{Contributions}

Study design: KS/NC/MC; data collection and analysis: KS/NC; manuscript preparation: $\mathrm{KS} / \mathrm{NC} / \mathrm{MC}$.

Declaration of conflicts of interest: Nothing to declare 


\section{ABSTRACT}

Aim: To provide information on the profile and practice of nurses in the United Kingdom who prescribe medication for pain.

Background: Pain is widely under-reported and under-treated and can have negative consequences for health and psychosocial wellbeing. Indications are that nurses can improve treatment and access to pain medications when they prescribe. While nurses working in many practice areas treat patients with pain, little is known about the profile, prescribing practice or training needs of these nurses.

Design: A descriptive questionnaire survey

Method: An online questionnaire was used to survey 214 nurses who prescribed for pain in the United Kingdom between May and July 2010. Data were analysed using descriptive statistics and non-parametric tests.

Results: Half the participants (50\%) worked in primary care, $32 \%$ in secondary care and $14 \%$ worked across care settings. A range of services were provided, including: general practice, palliative care, pain management, emergency care, walk-in-centres and out-ofhours. The majority (86\%) independently prescribed 1 to 20 items per week. Non-opioid and weak opioids analgesics were prescribed by most (95\%) nurses, whereas fewer (35\%) prescribed strong opioids. Training in pain had been undertaken by $97 \%$ and $82 \%$ felt adequately trained, although $28 \%$ had problems accessing training. Those with specialist training prescribed a wider range of pain medications, were more likely to prescribe strong opioids and were more often in pain management roles. 
Conclusion: Nurses prescribe for pain in a range of settings with an emphasis on the treatment of minor ailments and acute pain. A range of medications are prescribed and most nurses have access to training.

Relevance to clinical practice: The nursing contribution to pain treatment must be acknowledged within initiatives to improve pain management. Access to ongoing training is required to support nurse development in this area of practice in order to maximise benefits.

Keywords: nurse prescribing, pain, prescribing patterns, advancing nurse role 


\section{INTRODUCTION}

Epidemiological studies show that pain is commonly experienced (Crombie et al. 1999, Langley 2011). A National Health and Wellness survey of selected European countries reported the population prevalence of daily pain as 8.85\% (Langley 2011). If unresolved, pain can have a negative impact on health status, quality of life, employment, economic productivity and healthcare utilisation (Clinical Standards Advisory Group (CSAG) 2000, Breivik et al. 2006, Langley 2011).

Pain can be broadly classified as either acute or chronic, although these classifications can overlap. Acute pain is usually sudden in onset, of limited duration and often associated with injury or disease (CSAG 2000). It frequently occurs post-operatively, and is associated with a number of conditions from minor illnesses to injuries such as burns, trauma, musculoskeletal problems and long-term illnesses such as cancer (The Royal College of Anaesthetists \& The Pain Society (RCAPS) 2003). Treatment for acute pain ranges from simple analgesic medication (such as paracetamol and ibuprofen) to complex interventions such as patient controlled analgesia (RCAPS 2003). In the United Kingdom (UK), as in countries such as USA and Australia, specialist multi-disciplinary acute pain teams are advocated to provide pain relief in hospital settings (Nagi 2004). However, despite international attempts to improve pain services, evidence indicates that postoperative pain continues to be under-treated (Powell et al. 2009a).

Chronic pain is defined as pain lasting longer than the expected time of healing, or from disease processes in which healing does not take place (CSAG 2000). Across Europe 
over a quarter of adults (28\%) report chronic pain lasting at least 6 months, the most common being back pain (Fricker 2003). Patients with chronic pain make frequent use of healthcare services (Elliot et al. 1999, Breivik et al. 2006) and good practice recommends they are referred to specialist chronic pain management services which provide a range of medical and non-medical interventions (RCAP 2003). Despite this, most patients are treated by their general practitioner (Breivik et al. 2006) and evidence suggests that up to $50 \%$ of patients fail to achieve adequate pain control (Fricker 2003, Breivik et al. 2006). Similar concerns have been raised in relation to cancer pain; a recent international literature review concluded that pain is under-treated in almost $50 \%$ of cancer patients (Deandrea et al. 2008)

The complex nature of pain and its management means that in addition to acute hospital settings, patients with pain are frequently seen in primary care in general practice, walk in-centres and the community (Kinnersley et al. 2000, Salisbury \& Munro 2002, Hasselstrom et al. 2002). Recent changes to service provision due to increasing costs and demands for healthcare mean that nurses are frequently involved in providing these front line services (Jenkins-Clarke \& Carr-Hill 2001, Salisbury \& Munro 2002). There is evidence that nurse-led care contributes to improving access in primary care (Laurent et al. 2008). Nurse-led care can also improve the provision of specialist pain management (Mackintosh \& Bowles 1997, Courtenay \& Carey 2008a), and this is reported to be enhanced where nurses prescribe medicines (Stenner \& Courtenay 2008a). Internationally, analgesia is one of the medication groups most commonly prescribed by nurses (Courtenay \& Gordon 2009, Drennan et al. 2009, Fontana et al. 2000). However, 
little is known, about the extent to which nurses are involved in prescribing medicines for pain management. This is an important gap in knowledge given the potential for nurses to contribute to improving the management of acute and chronic pain (Bucknall et al. 2001, Creedon \& O’Regan 2010).

\section{BACKGROUND}

Increasing demand for healthcare and a shortage of doctors are driving forces behind initiatives to make better use of the expertise of all health professionals, including the expansion of nursing roles (World Health Organisation 2006). In response, the number of countries in which nurses have prescribing rights is increasing (Ball 2009, Kroezen et al. 2011). In the UK, registered nurses with at least three years clinical experience may undertake an additional qualification to prescribe (Department of Health (DH) 2006). Nurse prescribing is most prevalent amongst community and general practice nurses and is most often practiced within primary care, but is increasingly practiced in secondary care settings and by specialist nurses (Latter et al. 2010).

Worldwide, legislation enabling nurses to prescribe pain medication is subject to varying restrictions, particularly for strong opioids where a signature or agreement from a doctor is often required (Kaasalainen et al. 2007b, Logie \& Harding 2005, Berry \& Dahl 2007). In the UK, the two main forms of prescribing are Nurse Independent Prescribing (NIP) and Nurse Supplementary Prescribing (NSP). Through the former (NIP), nurses can prescribe any licensed medicine within their area of competence, including thirteen controlled drugs, which can be only be prescribed via certain routes of administration and 
indications (DH 2006, Home Office 2007). Through NSP, any medicine can be prescribed where an initial diagnosis has been made by a doctor and a Clinical Management Plan (CMP) agreed between the doctor, NSP and patient. In 2010 there were over 20,000 nurses qualified as Nurse Independent Supplementary Prescribers (NISP) in the UK (Nursing and Midwifery Council 2010).

While factors influencing the quality of pain management are complex (Manias et al. 2002, Kaasalainen et al. 2007a, Powell et al. 2009b), poor access to medicines, due to inadequate prescribing and staff shortages, is a known barrier to effective pain management (Schafheutle et al. 2001). It is reported that specialist pain nurses with prescriptive authority can contribute to improving access to appropriate pain treatment, reducing errors and enhancing the quality of care (Stenner \& Courtenay 2008a). Nurses who specialise in pain tend to be well qualified and trained in pain management (Williamson-Swift 2007, Stenner et al. 2011, Kaasalainen et al. 2007b). A survey of pain nurse specialists in the UK found that $12 \%$ had undertaken a prescribing qualification (Williamson-Swift 2007). By 2009, 28\% of nurses working in inpatient pain services were qualified nurse prescribers (Stenner et al. 2011). These nurses prescribed a range of medications, including opioid and non-opioid analgesics and a range of medicines to control side effects of analgesia, at an average of 20 items per week for inpatients. The majority $(86 \%)$ reported that prescribing had enhanced their ability to promote evidencebased practice for in-patient pain (Stenner et al. 2011).

There is some information available about the prescribing practices of nurses who are not dedicated pain specialists. A national evaluation of nurse prescribing in Ireland included 
an audit of 142 patient records and prescriptions issued by a total of 24 nurses in eight acute or specialist hospitals. Analgesics were the most frequently prescribed drugs, and pain was the most common reason for prescribing across a range of settings, including emergency departments, maternity and surgery (Drennan et al. 2009). Pain relief medication is also frequently prescribed by nurse practitioners in the USA, some of whom prescribe controlled substances (Fontana et al. 2000, Cipher et al. 2006). In Canada, the role of practice nurses and nurse practitioners in pain management have been explored (Kohr \& Sawhney 2005, Kaasalainen et al. 2007b, Kaasalainen et al. 2010). Of 16 nurse practitioners working in long-term care and providing treatment for patients acute, chronic and palliative care needs, $93.7 \%$ prescribed non-opioid analgesics, $62.5 \%$ NSAIDs and $12.5 \%$ prescribed opioids. Of the Advanced Practice Nurses (APNs) studied by Kohr \& Sawhney (2005), 58\% saw patients who required pain relief but only $13 \%$ specialised in pain management or palliative care. Most (56\%) influenced decisions to prescribe analgesics and $79 \%$ did this via providing advice to doctors and pharmacists. Within the UK, a survey conducted in 2009 reported pain as one of the five most common treatment areas for which all nurses prescribe alongside respiratory conditions, minor ailments, wound care and dermatology. Of the $42 \%$ who prescribed for pain, $53 \%$ worked in primary care $(53 \%), 30.5 \%$ in secondary care, $22 \%$ across primary and secondary care $(22 \%)$ and the remainder worked in other settings (Courtenay \& Gordon 2009).

The literature indicates a range of care settings in which nurses may encounter and prescribe for patients with a need for pain medication. Gaining a better understanding of 
the background, profile and prescribing practice of nurses who prescribe for pain will help inform education and support, as well as map development in this area of practice.

\section{AIM}

The aim was to provide a profile of UK nurses who prescribe medicines for patients in pain in terms of their background, experience, work settings and prescribing practice.

\section{METHODS}

\section{Design}

This was a descriptive questionnaire survey design. This paper reports on questionnaire data that formed part of larger survey designed to evaluate NISP in the UK.

\section{Sample}

A convenience sample of 214 UK nurses registered on the Association for Nurse Prescribing (ANP) membership database. The ANP is an independent organization providing support and education for nurses in their role as a prescriber. All participants were qualified as NISPs and prescribed medicines for the treatment of pain.

\section{Questionnaire}

Informed by previous research on nurse prescribing (Courtenay \& Gordon 2009, Courtenay \& Carey 2008c, Carey \& Courtenay 2010, Stenner et al. 2011), the questionnaire was set out in four sections and included fixed choice and open ended 
questions. There was an additional section with questions for nurses who prescribed for areas of practice other than pain, the findings for which are presented elsewhere.

The first section covered general demographic information, including: age, job title, geographical area, care setting, type of services provided, the number of nurse prescribers (NP) in the team, and future plans for NPs in their area of practice. Section two focused on prescribing qualifications and methods, levels of experience and areas of practice. Section three asked about prescribing for pain management, including the types of medication prescribed and the estimated number of items prescribed for pain in a typical week. Participants were then asked to indicate which of twelve ways they used their prescribing qualification in relation to the management of pain. The final section asked respondents about the level of training they had received to prescribe for pain, whether they had unfulfilled training needs and their preferred method(s) of learning for Continuing Professional Development (CPD).

\section{Procedure and ethical considerations}

All ANP members with a valid email address $(n=859)$ were sent an invitation to participate in the survey by the ANP administrator. The invitation outlined the purpose of the study and gave assurance that respondents would remain anonymous and that participation was voluntary. Those who wished to participate were asked to use an electronic link to access the on-line survey disseminated by an internet-based survey tool Survey Monkey@. After three email reminders, 439 (51.1\%) valid responses were received, of which $214(49.8 \%)$ prescribed medicines for pain. 
The questionnaire was piloted in March 2010 with 6 qualified nurse prescribers. Data from the pilot were not included in the main study. Minor revisions were made to the questionnaire as a result of the pilot. The survey was conducted between $1^{\text {st }}$ May and $22^{\text {nd }}$ June 2010. Ethical approval for the study was obtained from the relevant University ethics committee.

\section{Data analysis}

Microsoft Excel and SPSS version 17 were used for data entry and analysis. Descriptive statistics were used and non-parametric tests (Chi Square and Mann-Whitney) conducted to explore the differences between demographic variables and the number of items prescribed per week, number of products prescribed, and methods of using the

prescribing qualification. Free text comments were subject to content analysis and independently reviewed by a second researcher.

\section{RESULTS}

\section{Nurse profile and service provision}

The sample comprised 214 respondents who prescribed medications for the management of pain. Demographic details are provided in Table 1. Respondents were represented in all geographical areas across the UK and a variety of job titles were reported, the largest category being primary care based practice nurses and nurse practitioners $(35.5 \%, n=76)$. Just over $10 \%$ were emergency care or minor injury nurses $(10.3 \%, n=22)$ and $11.7 \%$ $(n=25)$ were pain or palliative care nurses. 
The majority $(82.2 \%, n=176)$ worked in a single care setting: half $(50.0 \%, n=107)$ in primary care, $32.2 \%(n=69)$ in secondary care. The remainder worked across primary, secondary and other settings $(13.5 \%, n=29)$, or worked in higher education, tertiary or intermediate care $(4.2 \%, n=9)$. The main areas in which services were provided were general practice $(37.8 \%, n=81)$ and hospital inpatient $(25.7 \%, n=55)$ or outpatient $(22.9 \%, n=49)$. The majority of participants were over 46 years of age $(69.2 \%, n=148)$, worked full time $(76.1 \%, n=163)$, had been qualified to prescribe for over three years $(64.9 \%, n=139)$ and had more than five years experience prior to prescribing $(72.4 \%$, $n=155)$.

\section{Prescribing role and practice}

All were qualified as NIP/NSPs. Sixty-seven (31.3\%) were the only non-medical prescriber (NMP) in their team, 29\% $(n=63)$ reported one other NMP, 12.1\% $(n=26)$ reported two others and $23.4 \%(n=50)$ reported three to ten or more NMPs in the team. Plans to increase NMP in their area were reported by $43.9 \%(n=94)$ and $22.9 \%(n=49)$ reported that team members were currently undertaking the prescribing course.

The majority $(87.4 \%, n=187)$ only used NIP, $8.4 \%(n=18)$ used both NIP and NSP and $1.9 \%(n=4)$ only used NSP. Of the 22 who explained why they used NSP, the reasons given were: legislative restrictions on prescribing controlled drugs $(50.0 \%, n=11)$, trust policy $(22.7 \%, n=5)$, personal preference $(18.2 \%, n=4)$ and only being qualified to use $\operatorname{NSP}(9.1 \%, n=2)$. 


\section{Prescribing for patients in pain}

Via NIP, 43.1\% ( $n=90)$ prescribed up to 5 items per week for patients in pain and a further $42.6 \%(n=89)$ prescribed between 6 and 20 items per week. As can be seen on Table 2, emergency care nurses prescribed significantly more frequently than other nurses (Mann-Whitney, $p=0.002)$. Of those using NSP, 34.5\% $(n=10)$ prescribed up to 5 items per week, 55.2\% ( $n=16)$ between 6 and 20 items, and the remainder $(10.3 \%, n=3)$ up to 50 items per week.

Acute pain, such as pain following injury or surgery, was the category most nurses prescribed for $(40.6 \%, n=87)$. Twenty-seven $(12.6 \%)$ prescribed for palliative pain, such as pain from cancer or advanced progressive illness, $26(12.1 \%)$ prescribed for chronic or long-term pain, such as headaches and back ache. A further $72(33.6 \%)$ prescribed for patients with a mix of the above pain types.

The types of medication prescribed for patients with pain are shown on Table 3. Almost all $(95.3 \%, n=204)$ prescribed non-opioid analgesics such as NSAIDs and paracetamol, whereas $34.6 \%(n=74)$ prescribed stronger opioids such as morphine. A range of adjunct therapies and medicines to control the side-effects of pain medications were prescribed. Nurses with pain or palliative care in their job title (see Table 4) were significantly more likely to prescribe strong opioids than other nurses (Chi-square, $p=0.000$ ).

\section{Additional use of prescribing qualification}

Participants were asked to indicate which of a number of medicines management activities they engaged in (see Table 5). In addition to issuing prescriptions to patients directly $(66.8 \%, n=143)$ or through hospital medicines charts $(37.3 \%, n=80)$, respondents 
also amended prescribed medication $(81.3 \%, n=174)$, recommended over-the-counter medications $(78.9 \%, n=169)$ and conducted medication reviews $(72.9 \%, n=156)$. Few (20\%, n=43) used patient group directions (PGDs), which act as a direction to a healthcare professional to supply and/or administer a prescription-only-medicine to a patient without referring back to a doctor for a prescription, or issued private prescriptions $(7.9 \%, n=17)$.

Respondents prescribed for a range of conditions in addition to pain, the four most common areas being minor ailments $(56.1 \%, n=120)$, wound care $(49.1 \%, n=105)$, respiratory problems $(47.7 \%, n=102)$ and dermatology $(41.1 \%, n=88)$.

\section{Specialist training in pain prescribing}

Nearly all $(97.2 \%, n=208)$ had received some form of training to prescribe for pain (see Table 1), most often as experiential or on-the-job training from clinicians or other healthcare professionals $(73.5 \%, n=158)$ or training included as part of another course such as minor ailments $(69.2 \%, n=148)$. A total of $48(22.4 \%)$ had undertaken specialist or post-graduate training in pain management. Pain and palliative care nurses were more likely than other nurses to have specialist training in pain (Chi-square, $p=0.000$ ) and those with specialist training prescribed a greater number of medication types (MannWhitney, $p=0.000$ ) and were more likely to prescribe strong opioids (Table 4, MannWhitney, $p=0.000$ ). There were no significant differences between those with and without specialist training in pain and the number of ways the prescribing qualification was used (Mann-Whitney, $p=0.961$ ) or frequency of prescribing by NIP (Mann-Whitney, $p=0.601$ ). 
Of the 210 participants who answered the question, the majority $(81.9 \%, n=173)$ felt adequately trained to prescribe pain medication, a minority $(8.6 \%, n=18)$ felt they were not adequately trained and 9.5\% (n=20) were unsure. Analysis using Mann-Whitney tests showed no significant differences between those who did and did not feel adequately trained and frequency of prescribing $(p=0.613)$, or range of ways in which the qualification was used $(p=0.547)$, however, caution should be given to these results due to the unequal group sizes.

\section{Continued Professional Development}

Sixty-one (28.5\%) reported to have CPD needs that they found difficult to fulfill and 73.8\% ( $n=158)$ had no unfulfilled CPD needs. Analysis of comments from 56 respondents (with some giving multiple answers) showed the main CPD needs were for a) ongoing updates on pain management, new treatments and best practice in prescribing for pain $(n=18)$, and b) training to expand knowledge of specific treatment areas, controlled drugs, or treating patients with complex pain and co-morbidities $(n=15)$. The main barriers to CPD were financial and time/staff shortages $(n=11)$, the availability of training at an appropriate level $(n=9)$ and lack of support for role development $(n=1)$.

The five most preferred methods for accessing CPD were: e-learning $(74.3 \%, n=159)$, journals $(69.6 \%, n=149)$, formal study days $(62.6 \%, n=134)$, prescribing forum $(57.5 \%$, $n=123)$ and work-based learning $(49.5 \%, n=106)$. Under half preferred individual study (45.3\%, n=97), non-accredited lunch or evening-time study sessions (42.9\%, $n=92)$. Smaller numbers preferred NMP conferences $(38.3 \%, n=82)$ or specialist clinical 
conferences $(26.5 \%, n=57)$ and the least preferred method was action learning sets $(7.5 \%$, $n=16)$.

\section{DISCUSSION}

Despite the limitations of a small sample size in proportion to the number of qualified nurse prescribers in the UK, the sample characteristics are similar to those previously reported in terms of age, hours worked, nursing experience and years qualified as a prescriber (Courtenay \& Carey 2008b, Courtenay \& Gordon 2009, Latter et al. 2010). It is possible, however, that the views and experiences of ANP members differ from nonmembers in that they may be more active in prescribing or keen to access support and education.

This survey describes, in more detail than has previously been available, the profile and practice of UK nurses who prescribe for patients in pain. Respondents included general practice nurses and nurses working in a variety of specialist areas and roles as well as those specialising in palliative care or pain management. Consistent with the prevalence of primary care based nurse prescribers nationally (Latter et al. 2010) the majority of participants $(50 \%)$ were based in primary care. In addition, a sizeable proportion worked in out-of-hours services $(12.6 \%)$ and walk-in-centres $(10.7 \%)$. More nurses who prescribed for pain worked in these settings than described in a sample of 840 nurses prescribing independently in England where $24.3 \%$ were based in secondary care and 4.4\% in walk-in-centres (Latter et al. 2010). 
The top four areas in which nurses prescribed in addition to pain (minor ailments, wound care, respiratory and dermatology) mirror the top presenting conditions reported for walkin centres and general practice settings offering same-day appointments (Salisbury \& Munro 2002, Kinnersley et al. 2000, Shum et al. 2000). As many participants provided general practice and immediate-access services, this suggests that a large proportion predominantly treated patients with minor injuries and illnesses who required analgesia as part of their treatment. The frequency with which non-opioid and weak opioid analgesics were prescribed supports this assumption, together with acute pain being the most commonly treated pain type. Nurses have been increasingly involved in providing services for minor injuries and illnesses as part of UK government policy to reduce waiting times and improve access to healthcare (DH 2000). Nurse prescribing was intended to facilitate such improvements (DH 2006) and these findings demonstrate its contribution to enhancing access to pain medication.

Strong opioids, including controlled drugs such as morphine, were prescribed by fewer $(34.6 \%)$ nurses and were significantly more likely to be prescribed by nurses in pain management roles and those with specialist training in pain. This finding indicates that nurses who prescribe controlled drugs undertake training for this task. Pain nurse specialists are known to have a high level of specialist education (Williamson-Swift 2007). A previous survey of nurses working in inpatient pain teams found that $75 \%$ prescribed strong opioid medication and that over $54 \%$ were qualified in pain management to masters or $\mathrm{PhD}$ level (Stenner et al 2011). Our findings reaffirm that pain nurse specialists have a higher level of training in pain than other UK nurses and that they prescribe a wider range of pain medications. 
Nurses are required to be competent in any given area for which they prescribe (DH 2006). Having specialist training and education in their area of practice has been linked to increased rates of prescribing for nurses working within dermatology (Courtenay et al. 2007) and diabetes (Courtenay \& Carey 2008c) and for doctors prescribing for chronic pain (McCracken et al. 2006). In contrast, no differences were found between the overall prescribing rates of those with or without specialist training in pain in this study. This may reflect that detailed specialist knowledge in pain management is not required to prescribe non-opioid analgesics for pain related to minor illness and injury. Very few $(2.8 \%, n=6)$, however, reported not to have received any training to prescribe for pain, the majority having undertaken a combination of on-the-job training, study days and conferences or to have studied pain as part of a wider course. Double the number of nurse prescribers in this survey (22.4\%) had undertaken specialist training compared to general practitioners surveyed in Southwest England, only 10\% of whom had specialist training in pain (McCracken et al. 2006).

Despite the relatively high level of training, around $18 \%$ of nurses were unsure if they were adequately trained to prescribe for pain and $28 \%$ had unmet CPD needs. Nurses have a professional responsibility to keep up-to-date with clinical and professional developments, including NMP policy and best practice in the management of conditions for which they prescribe (DH 2006). In turn, the employer has a responsibility to ensure that there is access to appropriate training or education, plus support for self-directed study. Specialist pain nurses are reported to use a wide variety of resources for CPD, including peer groups, journals, prescribing forum, newsletters, websites, conferences 
and formal training events (Stenner \& Courtenay 2008b). Similarly, a range of methods of accessing CPD were acceptable to participants in this study, although the preference was for more forms offering the greatest flexibility of access, namely e-learning and journals.

Access to CPD is particularly important where nurses are developing new areas of practice. When analysing changes to the service delivery areas in which nurses are involved, Latter et al. (2010) identified dermatology, pain management and infections as three areas with the largest increase in involvement since nurses had qualified to prescribe: there was a $44.6 \%$ increase in the number of nurses engaged in pain management as a new area of prescribing practice. This reiterates the importance of ongoing training in this area in which nurses frequently prescribe, particularly given the potential for nurses to improve the use of evidence-based approaches to pain management if given appropriate training and guidance (Stenner \& Courtenay 2008a, Creedon \& O'Regan 2010). This survey indicates that the number of nurses prescribing for pain is increasing and that NMP is expanding within teams where nurses prescribe for pain. Peer support is known to facilitate uptake and use of the prescribing qualification within practice and having more than one NMP per team is one way of optimising NMP and providing support (Otway 2001, Carey et al. 2010). As more nurses include pain as an area of practice development, access to appropriate and accessible training and support will become increasingly important if standards of care are to be maintained.

Importantly, this survey provides evidence of the range of ways nurses use their prescribing qualification. The most frequently reported activities were to amend 
medicine, recommend over-the-counter medicines and conduct medication reviews. Around $43 \%$ also recommended medication for GPs to prescribe; a practice reported elsewhere by nurses as a means of overcoming barriers to prescribing directly for patients (Stenner \& Courtenay 2007, Kohr \& Sawhney 2005). Correcting prescribing errors has previously been reported by specialist pain nurses (Stenner \& Courtenay 2008a) and children's nurses (Carey et al. 2009) as a means of using prescribing knowledge to improve care. Prescribing knowledge therefore extends beyond the act of issuing prescriptions to impact on many aspects of medicines management.

Compared to other countries, there are fewer restrictions in the UK on which groups of nurses are entitled to prescribe and the level of education and experience they require to do this (Kroezen et al. 2011). The wide range of contexts in which nurses prescribe pain medications is a reflection of the many and varied roles held by nurse prescribers in the $\mathrm{UK}$, as well as reflecting the prevalence of pain in the population. The findings therefore have implications for other countries that may wish to improve access to pain treatment, although the impact of nurse prescribing in this area remains to be fully evaluated.

\section{CONCLUSION}

This study demonstrates that nurses working in a wide variety of roles and settings in the UK are prescribing for pain and use their prescribing knowledge to influence medicines management. Indications are that a majority treat patients with acute pain related to minor injuries and illnesses who are seen within general practice and immediate-access settings such as emergency care, walk-in-centres and out-of-hours clinics. Those with specialist 
training in pain prescribe a wider range of pain medications, are more likely to prescribe strong opioids and are more often in pain management or palliative care roles.

\section{Relevance to clinical practice}

Nurses are increasingly involved in managing and prescribing medication for the treatment of pain and this change must be acknowledged if potential benefits for improving pain management are to be realised. While nurses may improve access to pain treatment, the quality of care they provide will depend on their level of specialist training and knowledge. The majority of nurses surveyed had undertaken training to prescribe for pain, however, access to ongoing training is vital to support nurse development in this area of practice as nurses extend their scope of practice. 


\section{References}

Ball J (2009) Implementing Nurse Prescribing. An updated review of current practice internationally. International Council of Nurses, Geneva.

Berry P \& Dahl J (2007) Advanced practice nurse controlled substances prescriptive authority: a review of the regulations and implications for effective pain management at end-of-life. Journal of Hospice \& Palliative Nursing, 9, 238-45.

Breivik H, Collett B, Ventafridda V, Cohen R \& Gallacher D (2006) Survey of chronic pain in Europe: prevalence, impact on daily life, and treatment. European Journal of Pain 10, 287-333.

Bucknall T, Manias E \& Botti M (2001) Acute pain management: implications of scientific evidence for nursing practice in the postoperative context. International Journal of Nursing Practice 7, 266-273.

Carey N \& Courtenay M (2010) An exploration of the continuing professional development needs of nurse independent prescribers and nurse supplementary prescribers who prescribe medicines for patients with diabetes. Journal of Clinical Nursing 19, 208-216.

Carey N, Stenner K \& Courtenay M (2009) Adopting the prescribing role in practice: exploring nurses views in a specialist children's hospital. Paediatric Nursing, 21, 25-29.

Carey N, Stenner K \& Courtenay M (2010) Stakeholder views on the impact of nurse prescribing on dermatology services. Journal of Clinical Nursing 19, 498-506. 
Cipher DJ, Hooker RS \& Guerra P (2006) Prescribing Trends by nurse practitioners and physician assistants in the United States. Journal of the American Academy of Nurse Practitioners 18, 291-296.

Clinical Standards Advisory Group (CSAG) (2000) Services for patients with pain. Department of Health, London.

Courtenay M \& Carey N (2008a) The Impact and Effectiveness of Nurse-Led Care in the Management of Acute and Chronic Pain: A Review of the Literature. Journal of Clinical Nursing 17, 2001-2013.

Courtenay M \& Carey N (2008b) Nurse independent prescribing and nurse supplementary prescribing practice: national survey. Journal of Advanced Nursing 61, 291-299.

Courtenay M \& Carey N (2008c) The Prescribing Practices of nurse independent prescribers caring for patients with diabetes: findings from a national questionnaire survey. Practical Diabetes International 25, 1-5.

Courtenay M, Carey N \& Burke J (2007) Independent Extended Nurse Prescribing for patients with skin conditions: a national questionnaire survey. Journal of Clinical Nursing 16, 1247-1255.

Courtenay M \& Gordon J (2009) A survey of therapy areas in which nurses prescribe and CPD needs. Nurse Prescribing 7, 255-262.

Courtenay M, Carey N \& Stenner K (2010) A questionnaire survey of nurse prescribing in the UK. University of Surrey, Guildford.

Creedon R \& O'Regan P (2010) Palliative care, pain control and nurse prescribing. Nurse Prescribing 8, 257-264. 
Crombie I, Croft P, Linton S, Le Resche L \& Von Korff M (eds) (1999) Epidemiology of Pain. Seattle, IASP Press.

Deandrea S, Montanari M, Moja L \& Apolone G (2008) Prevalence of undertreatment in cancer pain: A review of published literature. Annals of Oncology 19, 1985-1991.

Department of Health (2000) The NHS Plan: A Plan for Investment, A plan for reform. DH, London.

Department of Health (2006) Improving Patients' Access to Medicines: A Guide to Implementing Nurse and Pharmacist Independent Prescribing within the NHS in England. DH, London.

Drennan J, Naughton C, Allen D, Hyde A, Felle P, O'Boyle K, Treacy P \& Butler M (2009) Independent evaluation of the nurse and midwifery prescribing initiative. University College Dublin, Dublin.

Elliot AM, Smith BH, Penny KI, Smith WC \& Chambers WA (1999) The epidemiology of chronic pain in the community. Lancet 354, 1248-52.

Fontana S, Devine E \& Kelber S (2000) Nurse practitioner student prescriptive patterns. Journal of the American Academy of Nurse Practitioners, 12, 3-10.

Fricker J (2003) Pain in Europe. Mundipharma International Ltd, Cambridge. www.painineurope.com.

Hasselstrom J, Liu-Palmgren J \& Rasjo-Wraak G (2002) Prevalence of pain in general practice. European Journal of Pain 6, 375-385.

Home Office (2007) Public Consultation: Independent Prescribing of Controlled Drugs by Nurse and Pharmacist Independent Prescribers. Home Office, London. 
Jenkins-Clarke S \& Carr-Hill R (2001) Changes, challenges and choices for the primary health care workforce: looking to the future. Journal of Advanced Nursing 34, 842-849.

Kaasalainen S, Coker E, Dolovich L, Papaioannou A, Hadjistavropoulos T, Emili A \& Ploeg J (2007a) Pain management decision making among long-term care physicians and nurses. Western Journal of Nursing Research 29, 561-580.

Kaasalainen S, DiCenso A, Donald F \& Staples E (2007b) Optimizing the role of the nurse practitioner to improve pain management in long-term care. Canadian Journal of Nursing Research 39, 14-31.

Kaasalainen S, Marti-Misener R, Carter N, Dicenso A, Donald F \& Baxter P (2010) The nurse practitioner role in pain management in long term care. Journal of Advanced Nursing 66, 542-551.

Kinnersley P, Anderson E, Parry K, Clement J, Archard L, Turton P, Stainthorpe A, Fraser A, Butler CC \& Rogers C (2000) Randomised controlled trial of nurse practitioner versus general practitioner care for patients requesting "same day" consultations in primary care. BMJ 320, 1043-1048.

Kohr R \& Sawhney M (2005) Advanced Practice Nurses' Role in the Treatment of Pain. Canadian Nurse 101, 30-34.

Kroezen M, van Dijk L, Groenewegen P \& Francke A (2011) Nurse prescribing of medicines in Western European and Anglo-Saxon countries: a systematic review of the literature. BMC Health Services Research 11, 1-17.

Langley PC (2011) The prevalence, correlates and treatment of pain in the European Union. Current Medical Research Opinion 27, 463-80. 
Laurant M, Hermens R, Braspenning J, Akkermans R, Sibbald P \& Grol R (2008) An overview of patient's preference for, and satisfaction with, care provided by general practitioners and nurse practitioners. Journal of Clinical Nursing 17, 2690-2698.

Latter S, Blenkinsopp A, Smith A, Chapman S, Tinelli M, Gerard K, Little P, Celino N, Granby T, Nicholls P \& Dorer G (2010) Evaluation of nurse and pharmacist independent prescribing. University of Southampton and Keele University, Southampton.

Logie D \& Harding R (2005) An evaluation of a morphine public health programme for cancer and AIDS pain relief in Sub-Saharan Africa. BMC Public Health, 5, 1-7.

Mackintosh C \& Bowles S (1997) Evaluation of a nurse-led acute pain service: can clinical nurse specialists make a difference. Journal of Advanced Nursing 15, 3037.

Manias E, Botti M \& Bucknall T (2002) Observation of pain assessment and management: the complexities of clinical practice. Journal of Clinical Nursing 11, 724-733.

McCracken L, Hoskins J \& Eccleston C (2006) Concerns about medication and medication use in chronic pain. The Journal of Pain 7, 726-734.

Nagi H (2004) Acute pain services in the United Kingdom. Acute Pain 5, 89-107. Nursing and Midwifery Council (2010) Prescribing Update. Presentation by Culley F, Association for Nurse Prescribing Conference, $28^{\text {th }}$ September, Birmingham. Otway C (2001) Informal peer support: a key to success for nurse prescribers. British Journal of Community Nursing 6, 586-591. 
Powell A, Davies H, Bannister J \& Macrae W (2009a) Challenge of improving postoperative pain management: case studies of three actue pain services in the UK National Health Service. British Journal of Anaesthesia 102, 824-831.

Powell A, Davies H, Bannister J \& Macrae W (2009b) Understanding the challenges of service change: learning from acute pain services in the UK. Journal of the Royal Society of Medicine 102, 62-68.

Salisbury C \& Munro J (2002) Walk-in centres in primary care: a review of the international literature. British Journal of General Practice 53, 53-59.

Schafheutle E, Cantrill J \& Noyce P (2001) Why is pain management suboptimal on surgical wards? Journal of Advanced Nursing 33, 728-737.

Shum C, Humphreys A, Wheeler D, Cochrane M, Skoda S \& Clement S (2000) Nurse management of patients with minor illnesses in general practice: multicentre, randomised controlled trial. British Medical Journal 320, 1038-1043.

Stenner K \& Courtenay M (2007) A qualitative study on the impact of legislation on prescribing of controlled drugs by nurses. Nurse Prescribing 5, 257-261.

Stenner K \& Courtenay M. (2008a) The Benefits of Nurse Prescribing According to Nurses Prescribing for Patients in Pain. Journal of Advanced Nursing 63, 27-55.

Stenner K \& Courtenay M (2008b) The role of inter-professional relationships and support for nurse prescribing in acute and chronic pain. Journal of Advanced Nursing 63, 276-283.

Stenner K, Courtenay M \& Cannons K (2011) Nurse prescribing for inpatient pain in the United Kingdom: a national questionnaire study. International Journal of Nursing Studies 48, 847-855.

The British Pain Society (2010) Cancer pain management. BPS, London. 
The Royal College of Anaesthetists \& The Pain Society (RCAPS) (2003) Pain

Management Services: Good Practice. The Royal College of Anaesthetists \& The Pain Society, London.

Williamson-Swift A (2007) Education and training of pain nurse specialists in the United Kingdom. Acute Pain 9, 207-213.

World Health Organisation (2006) The world health report 2006: working together for

health. World Health Organisation, Geneva. 
Table 1: Demographic details of sample

\begin{tabular}{|c|c|c|}
\hline & $\begin{array}{l}n=\text { number of } \\
\text { responses }\end{array}$ & $\begin{array}{l}\% \text { of total } \\
\text { sample }\end{array}$ \\
\hline \multicolumn{3}{|l|}{ Hours worked $(n=213)$} \\
\hline Full time (more than 30 hours per week) & 163 & 76.1 \\
\hline 21-30 hours per week & 35 & 16.3 \\
\hline Less than 20 hours per week & 15 & 7.0 \\
\hline \multicolumn{3}{|l|}{ Age range $(n=213)$} \\
\hline Under 35 years old & 8 & 3.7 \\
\hline $36-45$ & 57 & 26.6 \\
\hline $46-55$ & 111 & 51.9 \\
\hline 56 and over & 37 & 17.3 \\
\hline \multicolumn{3}{|l|}{ Geographical location $(n=213)$} \\
\hline South East England & 41 & 19.2 \\
\hline Scotland & 29 & 13.5 \\
\hline London & 24 & 11.2 \\
\hline South West England & 24 & 11.2 \\
\hline Eastern England & 22 & 10.3 \\
\hline West Midlands & 20 & 9.3 \\
\hline North West England & 17 & 7.9 \\
\hline Yorkshire \& Humber & 11 & 5.1 \\
\hline Wales & 8 & 3.7 \\
\hline Northern England & 8 & 3.7 \\
\hline East Midlands & 8 & 3.7 \\
\hline Northern Ireland & 1 & 0.5 \\
\hline \multicolumn{3}{|l|}{ Job title (coded) } \\
\hline Practice nurses \& Nurse practitioners (primary care ) & 76 & 35.5 \\
\hline $\begin{array}{l}\text { Clinical nurses and nurse clinicians with no named specialty (including: nurse } \\
\text { consultant, matron, lead nurse, charge nurse, sister, nurse practitioners) }\end{array}$ & 50 & 23.4 \\
\hline $\begin{array}{l}\text { Nurses with named specialist area (other than pain or emergency), e.g. diabetes, } \\
\text { respiratory, long term care. }\end{array}$ & 27 & 12.6 \\
\hline Pain/palliative/Macmillan nurses & 25 & 11.7 \\
\hline Emergency care \& minor injury nurses & 22 & 10.3 \\
\hline Community nurses (District Nurse, Health Visitor, Community Matron) & 7 & 3.3 \\
\hline Other (managerial, higher education, prison, armed forces) & 4 & 1.9 \\
\hline Missing & 3 & 1.4 \\
\hline \multicolumn{3}{|l|}{ Service setting } \\
\hline General practice & 81 & 37.8 \\
\hline NHS hospital inpatient & 55 & 25.7 \\
\hline NHS hospital outpatient & 49 & 22.9 \\
\hline Community & 40 & 18.7 \\
\hline Out-of-hours & 27 & 12.6 \\
\hline Walk-in-Centre & 23 & 10.7 \\
\hline Education & 14 & 6.5 \\
\hline Community clinic & 8 & 3.7 \\
\hline Independent sector & 6 & 2.8 \\
\hline Prison or armed forces & 6 & 2.8 \\
\hline \multicolumn{3}{|l|}{ Years qualified as a prescriber } \\
\hline$<1$ year & 17 & 7.9 \\
\hline $1-3$ years & 58 & 27.1 \\
\hline $3-5$ years & 71 & 33.2 \\
\hline$>5$ years & 68 & 31.8 \\
\hline \multicolumn{3}{|l|}{ Experience in area of practice before becoming prescriber } \\
\hline$<1$ year & 5 & 2.3 \\
\hline $1-2$ years & 8 & 3.7 \\
\hline $2-5$ years & 43 & 20.1 \\
\hline$>5$ years & 155 & 72.4 \\
\hline \multicolumn{3}{|l|}{ Training to prescribe for pain (more than one response could be given) } \\
\hline Experiential on-the-job training & 158 & 73.8 \\
\hline Pain management included in another course & 148 & 69.2 \\
\hline Learning not accredited by a university (e.g. study days, conferences) & 111 & 51.9 \\
\hline Specialist course in pain management & 39 & 18.2 \\
\hline Post graduate diploma or certificate in pain & 12 & 5.6 \\
\hline Masters or PhD related to pain & 17 & 7.9 \\
\hline No training & 6 & 2.8 \\
\hline
\end{tabular}


Table 2. The number of items prescribed in a typical week for pain management by nurse prescribers by job category

\begin{tabular}{|l|l|l|l|l|l|l|l|}
\hline & \multicolumn{7}{|c|}{ Number of items prescribed } \\
\hline Job Title & $<\mathbf{1 0}$ & $\mathbf{1 1 - 2 0}$ & $\mathbf{2 1 - 3 0}$ & $\mathbf{3 1 - 4 0}$ & $\mathbf{4 1 - 5 0}$ & $\mathbf{> 5 0}$ & Total \\
\hline $\begin{array}{l}\text { Practice nurses \& Nurse practitioners } \\
\text { (primary care) }\end{array}$ & 46 & 12 & 10 & 4 & 1 & 0 & 73 \\
\hline Clinical nurses with no named specialty & 31 & 9 & 4 & 2 & 0 & 0 & 46 \\
\hline Pain or palliative care nurses & 14 & 8 & 1 & 0 & 1 & 0 & 24 \\
\hline Emergency care or minor injury nurses & 6 & 9 & 2 & 1 & 1 & 3 & 22 \\
\hline Nurses with other named specialty & 25 & 2 & 0 & 0 & 0 & 0 & 27 \\
\hline Community nurse & 6 & 1 & 0 & 0 & 0 & 0 & 7 \\
\hline Other & 4 & 0 & 0 & 0 & 0 & 0 & 4 \\
\hline Missing job title & 1 & 2 & 0 & 0 & 0 & 0 & 3 \\
\hline Total & $\mathbf{1 3 3}$ & $\mathbf{4 3}$ & $\mathbf{1 7}$ & $\mathbf{7}$ & $\mathbf{3}$ & $\mathbf{3}$ & $\mathbf{2}$ \\
\hline \hline Emergency care or minor injury nurses & 6 & 9 & 2 & 1 & 1 & 3 & 22 \\
\hline Other nurses & 127 & 34 & 15 & 6 & 2 & 0 & 184 \\
\hline & \multicolumn{7}{|l|}{ Mann-Whitney } \\
\hline
\end{tabular}

\section{Table 3. Medications prescribed for pain management}

\begin{tabular}{|l|c|c|}
\hline Analgesic medication & $\begin{array}{c}\text { Number } \\
\text { prescribing }\end{array}$ & $\begin{array}{c}\text { \% of sample } \\
\text { ( } \boldsymbol{n = 2 1 4 )}\end{array}$ \\
\hline Non-opioid analgesics (e.g. ibuprofen, paracetamol) & 204 & 95.3 \\
\hline Compound preparations (e.g. co-codamol) & 184 & 86 \\
\hline Weak opioids (e.g. codeine phosphate, Tramadol) & 158 & 73.8 \\
\hline $\begin{array}{l}\text { Strong opioid analgesics (e.g. morphine, } \\
\text { buprenorphine, Oxycodone) }\end{array}$ & 74 & 34.6 \\
\hline Adjuvant and medication for side effects & & 64.5 \\
\hline Laxatives & 138 & 58.9 \\
\hline Anti-emetics & 126 & 37 \\
\hline Anti-depressants & 79 & 24.8 \\
\hline Anti-convulsants & 53 & 8.4 \\
\hline Other adjuvant therapy & 18 & \\
\hline Oth: & & \\
\hline
\end{tabular}

Other: steroids (6), topical anaesthetics (4), TENS machine (1), Naloxone (3), ketamine (1), antispamodics (2), nitrous oxide (1) 
Table 4. The effect of nurses with a pain job title and specialist training on the prescribing of opioids

\begin{tabular}{|c|c|c|c|c|c|c|}
\hline \multirow{3}{*}{ Pain job title } & \multicolumn{4}{|c|}{ Prescribe strong opioids } & & \multirow{3}{*}{ Chi-Square } \\
\hline & \multicolumn{2}{|c|}{$\overline{\text { Yes }}$} & \multicolumn{2}{|c|}{ No } & & \\
\hline & $n$ & $\%$ & $n$ & $\%$ & Total & \\
\hline Yes & 23 & 100 & 0 & 0 & 23 & \multirow{3}{*}{$\begin{array}{l}X^{2} 49.111 \\
p=0.00\end{array}$} \\
\hline No & 51 & 26.9 & 138 & 73.0 & 189 & \\
\hline Total & 74 & 34.9 & 138 & 65.1 & 212 & \\
\hline Specialist training & $n$ & $\%$ & $n$ & $\%$ & Total & \multirow{4}{*}{$\begin{array}{l}X^{2} 37.705 \\
P=0.00\end{array}$} \\
\hline Yes & 34 & 72.3 & 13 & 27.7 & 47 & \\
\hline No & 39 & 23.9 & 137 & 84.0 & 163 & \\
\hline Total & 73 & 34.8 & 137 & 65.2 & 210 & \\
\hline
\end{tabular}

Table 5. Methods of using the prescribing qualification for patients who require medicines for pain management

\begin{tabular}{|l|c|c|}
\hline Method & $\begin{array}{c}\text { Number using } \\
\text { method }\end{array}$ & $\begin{array}{c}\text { \% of sample } \\
(\boldsymbol{n}=\mathbf{2 1 4})\end{array}$ \\
\hline $\begin{array}{l}\text { Amend prescribed medication (i.e. stop, alter or correct } \\
\text { dose) }\end{array}$ & 174 & 81.3 \\
\hline Recommend patient buys medication over the counter & 169 & 78.9 \\
\hline Medication review & 156 & 72.9 \\
\hline Issue FP10 direct to patient & 143 & 66.8 \\
\hline Recommend medication via telephone, email/letter to GP & 93 & 43.4 \\
\hline Prescribe via hospital medication charts & 80 & 37.3 \\
\hline Issue hospital specific prescription direct to patient & 65 & 30.3 \\
\hline Remote prescribing by telephone, email or fax & 58 & 27.1 \\
\hline Sign FP10 issued via GP repeat prescribing system & 58 & 27.1 \\
\hline Recommend medication via patient hospital notes & 61 & 28.5 \\
\hline Supply and administer medicines via PGD & 43 & 20 \\
\hline Issue private prescription direct to patient & 17 & 7.9 \\
\hline
\end{tabular}

Abbreviations: GP = General Practitioner, PGD = Patient Group Direction, FP10 = a prescription form purchased by a trust for prescribing medication that is to be dispensed by community pharmacies in the UK 